\title{
\ل
}

\section{Paulista Invaders: PLAY!}

Suzete Venturelli

Universidade de Brasília, Brasília-DF, Brasil

suzeteventurelli@gmail.com

\section{Introdução}

O conceito de interação passou a ser mais elaborado com a interface humano-computador se efetuando por meio de estruturas multimidiáticas, no qual o feedback e a retroatividade possibilitada pela cibernética se tornaram mais apropriados para a sensibilidade e a estética. Em alguns sistemas artísticos informacionais, verifiquei como se dá a estética da relação, da troca e da interação entre humano e máquina e entre máquinas.

Além da aproximação da arte com a ciência, o que conta é também a noção mesmo de sujeito e de correlação com o domínio do singular que, no sublime tecnológico de Mario Costa (1995), se ameniza até desaparecer. O sujeito individual é ultrapassado pelo hipersujeito tecnológico, onde as subjetividades individuais não interessam tanto quanto as subjetividades do hipersujeito, que fazem surgir novas modalidades do sublime, provocadas pela participação e posteriormente pela interatividade a partir de projetos colaborativos e de dispositivos de contatos a distância multiusuários, como podem ser observados nos trabalhos de gamearte.

O game e a arte computacional sempre caminharam juntos, embora com finalidades diferentes. Os caminhos da tecnologia e da interatividade são os caminhos de convergência. Nos últimos anos assistimos a uma verdadeira explosão de trabaIhos envolvendo a linguagem do videogame na arte. A gamificação da arte dependeu dos avanços da tecnociência e tem como característica sistemas emergentes, multiusuários, em conexão com redes sociais computacionais. Com a linguagem dos games, busquei envolver as pessoas, usuários dos sistemas, em sensações 
interativas e de compartilhamento de espaços virtuais em instalações e em conexões sociais. Considero que a metodologia de criação de gamearte contempla ideias contemporâneas de intervenção no contexto político, social e urbano e tem fundamentos teóricos originados das áreas da ciência da computação, da arte e da comunicação.

Como exemplo de gamearte ou gamificação da arte, descrevo alguns trabalhos que desenvolvo ${ }^{1}$, muitas vezes em equipe, desde os anos 1997, quando surgiu a linguagem de programação VRML (Virtual Modeling Mackup Language), para a rede Internet, e os Engines de vídeo games.

O neologismo Gamearte começou a ser usado no laboratório para designar obras artísticas que se apropriam da ideia de jogo computacional, recorrendo a regras flexíveis e a narrativas pouco convencionais. Esta categoria da arte computacional está apoiada em fundamentos teóricos originados das áreas da ciência da computação, da arte e da comunicação, principalmente. A interatividade é um conceito pertinente na gamearte, pois proporciona o surgimento de uma cultura de interação numérica, com regras estabelecidas em 1961, pelo grupo de estudantes do Massachusetts Institute of Technology (MIT), que testava pela primeira vez Spacewar, um jogo eletrônico desenvolvido em um enorme computador que custava milhares de dólares. Eles queriam criar algum tipo de demonstração, e por isso criaram algumas regras que seu programa deveria seguir:

1. Deveria demonstrar as capacidades do computador, usando quase todo seu potencial.

2. Deveria ser interessante e interativo (diferente toda vez que rodado).

3. Deveria envolver o usuário de maneira atrativa e prazerosa, deveria ser um jogo.

Estas regras são interessantes também no contexto da arte, pois pode provocar a inserção do espectador como um elemento fundamental na poética artística, sem o qual a obra não existe.

Mas, o mais interessante na nova forma imagética que surgia para nós ficou conhecido como Realidade Virtual (RV), formada por imagens tridimensionais e interativas. A técnica era a de simulação e procurava implementar a ideia de proporcionar a sensação do "estar lá", oferecendo, pelo menos ao olho, o que ele teria visto se

1 Disponível em: HTTP://suzeteventurelli.ida.unb.br. 
tivesse estado lá e, mais importante, fazendo com que a imagem, ao ser manipulada, pudesse mudar instantaneamente de acordo com o ponto de vista. Nossa percepção, nesses ambientes de realidade espacial, é determinada por várias informações visuais tais como o tamanho relativo, o brilho e o movimento angular, sendo que uma das mais importantes é a perspectiva, que pode proporcionar a estereovisão, forma binocular em que cada olho vê uma imagem diferente. É importante destacar que em conjunto com a RV, surge uma outra novidade que são as imagens inteligentes, proporcionadas pela tecnologia de Inteligência Artificial ou simplesmente IA. A IA é utilizada no videogame, principalmente nas interações de causa e efeito, realizadas por aqueles que experimentam, interpretam ou exploram os games. A IA vem permitindo, até hoje, o intercâmbio de experiências e conhecimento, de entretenimento e de relações; de contemplação e de sensações. A IA confere comportamento aos personagens do gamearte, que se deslocam no espaço conforme ações dos jogadores, que interagem por meio do Joystique. Para André Kishimoto², a IA corresponde à simulação do comportamento humano inteligente. Ela é o cérebro por trás de máquinas, como as encontradas em filmes de ficção científica, enquanto que, para os pesquisadores, é uma fonte infinita de desafios e estudos sobre como recriar um ser inteligente através do uso de computadores. Para o autor, existem desenvolvedores que consideram a interface do jogo com o usuário e algoritmos de movimento e colisão como parte da área de estudos em IA.

O autor cita que foram os algoritmos de IA determinísticos, junto com padrões de movimento, utilizados nos primeiros jogos eletrônicos da história, e são compostos por movimentos aleatórios, algoritmos de perseguição e evasão. Em outras palavras, os movimentos aleatórios são implementados obtendo um valor aleatório e incrementando a posição de um personagem com tal valor. O algoritmo de perseguição verifica a posição de um personagem 1 em relação à posição de um personagem 2, e avança em direção a ele. O algoritmo de evasão faz o personagem 1 se distanciar do personagem 2. Assim, explica o autor que, os padrões de movimento fazem com que um personagem se movimente em um determinado padrão, por exemplo, um personagem pode fazer uma ronda em uma área retangular.

2 Disponível em: http://www.programadoresdejogos.com/trab_academicos/andre_kishimoto.pdf. Acesso em 10 dez. 2012. 
O autor esclarece que a IA para jogos é complexa e existem outras técnicas que não foram discutidas e que são aplicadas nos jogos, como o algoritmo de Fussy, A-Life, algoritmos de flocking para simular o movimento em grupo de monstros, pássaros, peixes, entre outros. Outro método recorre às redes neurais, onde os personagens necessitam de aprendizado através das escolhas do jogador. Outros jogos implementam a IA através de scripts, possibilitando que qualquer pessoa possa criar novos tipos de NPC's (non-player characters) ou modificar um personagem já existente de acordo com o seu estilo de jogo. Esse tipo de IA (também conhecido por Extensible AI) é baseada fortemente em sistemas de regra.

Nesse sentido, consideramos que em alguns momentos específicos a estética da comunicação, por onde transitam também os jogos, se depara com o sublime tecnológico, fazendo com que a experiência estética se desloque do interior para o exterior, se exteriorizando. Permite, assim, que o interior do sujeito assuma uma experiência a partir do exterior, não no sentido onde o espírito se objetiva, mas no sentido onde ele se apresenta como um estado de coisas.

A essência do produto artístico é renegada e tecnologicamente transferida ao exterior pelo intermediário das interfaces mente e máquina, ou seja, máquinas sinestésicas. Na estética do sublime tecnológico, a forma não tem tanta importância, pois ela se identifica com o conceito, com a não-forma, com o aleatório, com a sorte, com o efêmero, com o transitório, quer dizer, com a chegada do fluxo dos eventos. Isso, para nós, parece ser o novo sentido que a pesquisa estética está tomando sob o impulso das tecnologias computacionais do som, da imagem, da comunicação, da espacialidade, entre outros.

\section{Exposição PLAY!}

Um exemplo interessante da sedutora estética da gamearte pôde ser apreciado por quem passou pela Avenida Paulista em São Paulo diante do edifício FIESP/ SESI que se transformou na maior galeria de arte digital a céu aberto da América Latina. Ali, aconteceu a exposição PLAY! (2013) que faz com que a cidade esteja na rota mundial de cidades que integram arte digital ao seu tecido urbano, ou seja, utilizam-se do termo "media facade" para transmitir viagens artísticas e sociais. 0 edifício piramidal de 1979 continua com sua fachada "colmeia" forrada com mais de 100 mil lâmpadas de LED (light emiting code). Esta cadeia elétrica possibilita a transmissão de até 4,3 bilhões de combinações de cores. 
A exposição foi inspirada no universo dos videogames, intitulada PLAY!. A curadora Marília Pasculli (2013), da produtora Verve Cultural, comentou que gamearte é considerada uma das manifestações artísticas emergentes mais interessantes da atualidade. Não só por dissolver os limites entre as diferentes formas de arte - já que a forma "inculta" de entretenimento dos videogames alcançou uma posição importante na estética intelectual no mundo artístico - mas também por obter um potencial interativo, um valor cultural que vai além da imagem exibida em diferentes meios, não interativos.

A partir do tema games, a galeria de arte digital do SESI - novamente com a Verve Cultural - transcendeu o fato de apenas exibir as obras digitais e abriu espaço também para a interação com o público.

Foram transmitidas seis obras digitais de artistas contemporâneos, sendo três delas interativas (jogos, executáveis) e três visuais (configuradas em vídeo). Quem passou pela Avenida Paulista durante as noites deste período apreciou vários aspectos da história dos videogames, tais como: o jogo de corrida, a estética do atirador, a navegação do labirinto, a dicotomia do ganhar e perder, e a visão com perspectiva em terceira pessoa. O Paulista Invaders, proposta do Midialab, com a participação de Suzete Venturelli, Bruno Ribeiro, Francisco de Paula Barretto e André Bassani Freitas, foi inspirado no clássico "Space Invaders", de 1978. Neste caso, o jogo vem com uma proposta de sustentabilidade, onde as criaturas do espaço e as armas dão lugar aos carros e as bicicletas. $\mathrm{Na}$ Avenida Paulista, os transeuntes contavam com os monitores do SESI que ensinavam as pessoas a jogar em tempo real com o Ipad (figura1). 


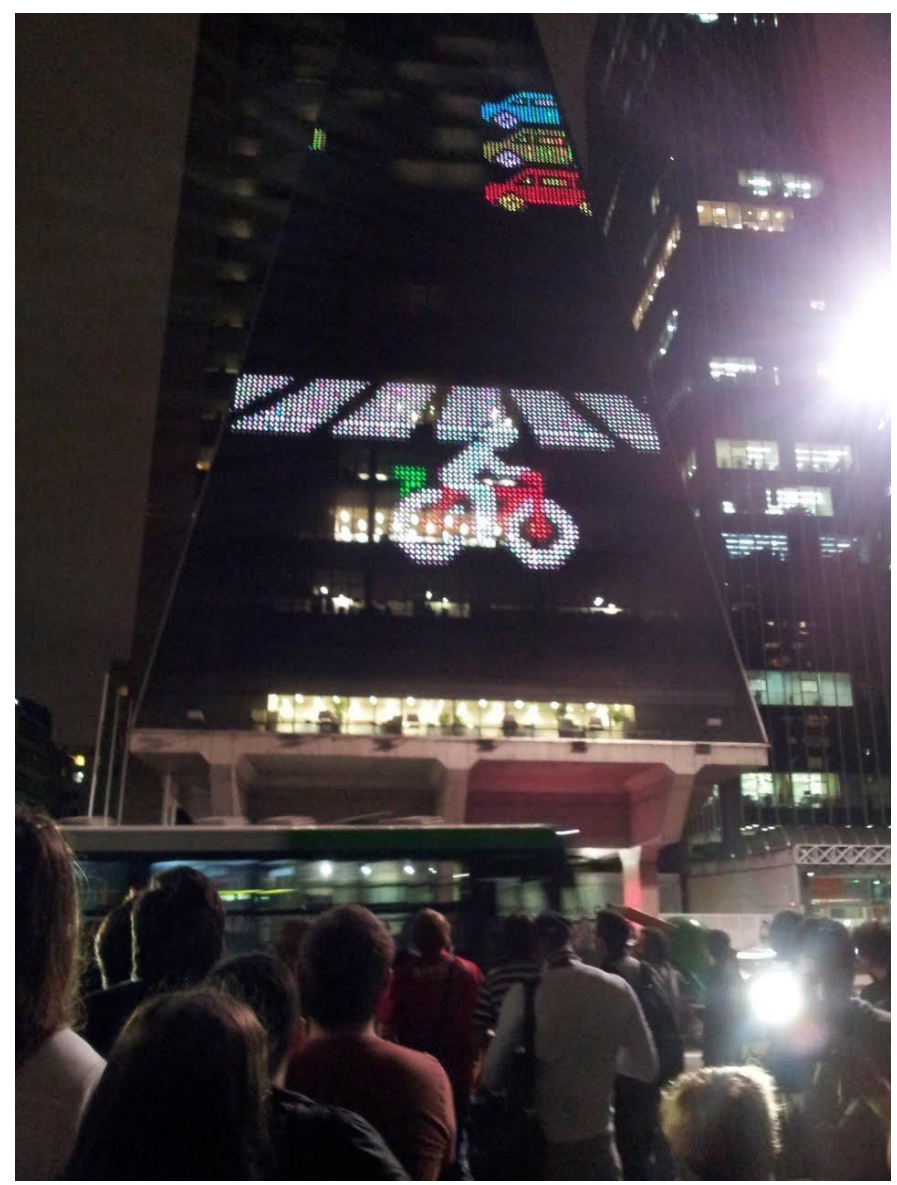

(figura1) Abertura da exposição com Paulista Invaders.

Fonte: acervo pessoal

O resultado foi bastante positivo. A interatividade com jogabilidade ocorreu em função do sistema wifi de longa distância implementado. O pedestre, para ter uma visão do jogo, ficava posicionado do outro lado da Av. Paulista, olhando o edifício de baixo para cima. Com o IPad ocorria a comunicação e o jogo era vivenciado em tempo real. Ressaltamos que o painel de Leds restringiu a resolução do game em $168 \times 221$ pixels, determinando sua estética. A forma da sua estética é denominada hoje de pixelart, pois remete a sistemas computacionais mais antigos e consoles de videogame que dispunham de resolução de limitada. O termo pixelart foi cunhado por Adele Goldberg e Robert Flegal numa comunicação durante o evento ACM, em 1982. Relembra esteticamente pontos de bordado, assim como as tramas da cestaria ou ainda o pontilhismo nas artes plásticas, embora o quadrado seja seu aspecto final. O pixel (picture element) é a menor unidade de informação digital de um monitor, no qual é possível atribuir uma cor. Num monitor de comutador, todo 
Pixel é composto por um conjunto de 3 pontos: verde, vermelho e azul.

Nos monitores atuais, cada um destes pontos é capaz de exibir 256 tonalidades diferentes (o equivalente a 8 bits), e combinando tonalidades dos três pontos é então possível exibir pouco mais de 16.7 milhões de cores diferentes (exatamente 16.777.216). Em resolução de $640 \times 480$ temos 307.200 pixels, a $800 \times 600$ temos 480.000 pixels, a $1024 \times 768$ temos 786.432 pixels e assim por diante. O monitor do futuro OLED é antes de tudo um monitor ecológico, pois tem grande eficiência energética uma vez que conseguem gastar menos energia que os monitores LCD mais avançados. Devido ao fato de usar em sua tecnologia Compostos Orgânicos Carbono (OLED: Organic LED) em vez de simples metais semi-condutores, com os monitores OLED temos pela primeira vez um monitor em que os pixels têm luz própria suficiente para brilhar sozinhos, não precisando de iluminação extra ou indireta (sidelight e backlight), como temos nos Monitores de Plasma e LCD e também nos antigos CRT (tubos de raios catódicos). A tecnologia determina também a estética computacional, como se pode concluir, a partir desta análise que considerou a evolução dos monitores.

A revista Galileu ${ }^{3}$ online comentou que não se trata apenas de jogar vídeo game na fachada de um prédio - o que por si só já seria de uma diversão desconcertante. Além de incentivar a ocupação de espaços públicos, o trabalho atualiza a temática dos jogos, chamando atenção para assuntos urgentes. Space Invaders vira Paulista Invaders e as naves viram bicicletas que, em vez de balas, atiram flores nos carros para que eles mantenham uma distância segura. Uma obra com esse conteúdo, nesse local, depois do absurdo acidente ocorrido na época, é ou não é um manifesto político? Com um detalhe: se fosse um curta-metragem ou um texto, ficaria chato e não prenderia a atenção de quase ninguém que passasse pela calçada.

Outro jogo apresentado na exposição foi o LummoBlocks, que possibilitou a interação dos participantes via sensor de movimento corporal (como o game Wii). A obra criada em Barcelona, na Espanha, é uma nova versão do lendário jogo "Tetris", onde os movimentos corporais são rastreados e os próprios jogadores viram peças do game. Além destas, serão exibidas mais quatro obras digitais.

3 Disponível em:http://revistagalileu.globo.com Acesso em abr. 2013. 
Segundo a curadora, a exibição, partiu da ideia de que os jogos estão se tornando uma tendência cultural e se inserindo cada vez mais na vida urbana. E configura-se como a primeira mostra de game arte interativa e a céu aberto no Brasil. Enquanto os videogames são vistos como uma organização do "jogar" através de um espaço na tela, o que, então, essa noção de jogar pode oferecer para os espaços públicos? Qual a contribuição que a narrativa dos videogames pode oferecer à nossa condição cultural? As obras incluídas em PLAY! Devem ajudar a desvendar as questões propostas acima. A mostra PLAY! da galeria de arte digital do SESI-SP, apresentou seis obras conforme foram categorizadas e descritas pela curadoria.

Obras digitais interativas - que contaram com monitores do SESI munidos da tecnologia necessária para os jogos: Paulista Invaders (2013) - Suzete Venturelli e equipe Midialab (Universidade de Brasília). A obra aborda a ética do cidadão, com foco em dois dos principais problemas de São Paulo: o tráfego de veículos e a poluição do ar. Este jogo interativo, e em tempo real, foi desenvolvido com exclusividade para a exibição PLAY! e será interativo através de um tablet. Fazendo referência a um dos jogos de tiro mais antigos, o icônico "Space Invaders" desenvolvido por Tomohiro Nishikado e lançado em 1978, o "Paulista Invaders" defende uma vida verde e sustentável. O jogo de tiro se estrutura em duas dimensões da plataforma de Leds, onde o jogador controla uma bicicleta movendo-a embaixo da tela no sentido horizontal. Para se defender, a bicicleta atira flores nos carros para mantê-los longe. O game explicita uma tentativa de humanizar a Av. Paulista, questionando a qualidade de vida, saúde e despoluição do ar. Propõe a discussão sobre o uso da bicicleta como agente do trânsito capaz de ajudar a desafogar as vias, além de ressaltar a fragilidade do ciclista ao tentar ocupar o espaço da rua.

O outro trabalho, LummoBlocks (2010) proposto pelo grupo espanhol Lummo lembra o jogo Tetris, com a diferença que foi jogado na rua por duplas. O mecanismo é semelhante ao original; porém, nessa versão, os jogadores controlam as peças com os movimentos corporais, em tempo real, através de sensores. A fachada do edifício mostrou uma versão super dimensionada de Tetris. Um jogador controla a rotação das peças (tijolos), e o outro controla aonde a peça vai cair através de movimentos paralelos ao primeiro jogador. O jogo incentiva a interação, a comunicação, e a colaboração entre os jogadores dentro do espaço. O jogo, portanto, transcende a distinção entre o ato de jogar e a vida comum e chama a atenção 
para nossos espaços urbanos que podem ser modificados, de acordo com a vontade e a visão coletiva dos cidadãos.

Labirintos Invisíveis (2013) de Andrei Thomaz consistiu numa versão do trabalho originalmente desenvolvido em 2008, para web e para celulares Java, baseado no conto Os dois reis e os dois labirintos, de Jorge Luis Borges. O jogo apresenta duas mecânicas opostas e os jogadores interagem através de iPads. A primeira propõe o desafio de atingir a saída de um labirinto que é completamente invisível no início da partida. Cada vez que o jogador move-se dentro do labirinto e esbarra numa parede, esta se torna visível. Entretanto, como o tempo é limitado, não se pode perder tempo tentando tornar todo o labirinto visível. Já na segunda mecânica, o labirinto é visível no início da partida mas, a cada segundo, algumas de suas paredes são apagadas. Porém, elas continuam impedindo a passagem do jogador. Assim, o jogo torna-se mais difícil ao longo do tempo, já que o jogador não vê mais quais são os obstáculos no caminho em direção à saída e é obrigado a deslocarse por tentativa e erro. De uma maneira quase surreal, a obra desafia a memória do jogador do mapa real do labirinto. A natureza icônica do labirinto remete ao popular jogo de 1980, o Pac-Man, considerado um dos clássicos dos videogames.

Outras obras digitais visuais que participaram foram: Supercut (2007-2013) de Mark Essen (EUA), que criou uma espécie de colagem em vídeo de várias obras anteriores. Entre elas, Nidhogg (2013), Basquetebol Jetpack (2010), Tickleplane (2012), e Flywrench (2007). Tais jogos fundem a estética dos jogos clássicos de fliperama com a abstração geométrica e a Op-art. O trabalho Pixels Deslocados (2013), de Alberto Zanella, retratou elementos dos games clássicos que se tornaram precursores do design contemporâneo e do imaginário coletivo, como Pac-man, Tetris, Super Mario Bros, Another World, Pong, dentre outros. A obra faz uma releitura destas criaturas em situações que fogem do ambiente onde elas sempre estiveram contidas, abusa das cores vibrantes e de grafismos pixelados, e aborda a nostalgia dos traços simples e as alternativas criativas da computação gráfica nas décadas de 70 e 80 . Curiosmanete, os games clássicos são considerados produto artístico e foram recentemente adquiridos como acervo do renomado Museu de arte moderna MoMA (Museum of Modern Art - New York).

A proposta The Game Is Over (2009) do grupo Les Liens Invisibles (2013) consiste num trabalho em vídeo construído a partir das sequências do videogame "Ou- 
tRun", de 1986, lançado pela SEGA e projetado por Yu Suzuk. No game original, o jogador controla uma Ferrari vermelha, com perspectiva em terceira pessoa. 0 carro já está com uma garota no banco do passageiro. Eles transitam pela estrada numa paisagem agradável. O videogame "OutRun", foi um dos primeiros simuladores de direção que dava ao jogador a opção de escolher rotas, o que talvez tenha inspirado os artistas a escolherem este jogo para ser modificado, e ainda instigar alguma esperança no ser humano para que ele recupere o controle do desenvolvimento cultural.

Sobre os artistas, é interessante citar que, Alberto Zanella é Diretor de arte, motion graphics designer e animador 3D. Produziu animações no início dos anos 80, (com computadores 8bits ligados em TVs e toca-fitas), até as projeções multitelas 3D ou mesmo as projeções mapeadas. Criador do projeto Pixels Nervosos, que foge um pouco do conceito de projection mapping em edifícios e monumentos, procura detalhes da cidade, lugares que ninguém presta atenção, uma maneira de dar personalidade e chamar o olhar dos habitantes para locais abandonados e esquecidos. Produz ações pontuais, como os grafites de pumpkins e smiles animados em 3D e projetados a revelia, em prédios de São Paulo, simplesmente pelo prazer de criar curiosidade e questionamento.

Andrei Thomaz de São Paulo é Mestre em Artes Visuais pela ECA/USP e professor no Instituto Europeo di Design em São Paulo. Sua produção artística abrange diversas mídias, digitais e analógicas, envolvendo também colaborações com outros artistas, entre as quais encontram-se performances sonoras e instalações interativas. Em 2006, foi um dos artistas recebedores do Prêmio FIAT Mostra Brasil. Em 2007, foi um dos ganhadores do Prêmio Atos Visuais 2007, da FUNARTE; e em 2009, foi um dos premiados do $63^{\circ}$ Salão Paranaense. Junto com Daniel Escobar e Marina Camargo, foi um dos ganhadores do Prêmio de Ocupação dos Espaços da Funarte 2010, com o projeto Lugares/Representações. Vive e trabalha em São Paulo, SP. Já Les Liens Invisibles - Itália é grupo italiano formado pelos artistas Clemente Pestelli e Quintini Gionatan. Seu trabalho é uma recombinação eclética de cultura de rede pop, técnicas de engenharia inversa, subversão das mídias sociais e variados tipos de manipulações de sistemas eletrônicos. A maioria de suas obras e intervenções online tem sido internacionalmente exposta em galerias, museus (MAXXI Rome, New School of New York, KUMU Art Museum of Talinn) e 
Festivais Internacionais de Arte Multimídia (Venice Biennale, Piemonte SHARE Festival, Transmediale). Receberam a distinção honorária no festival Transmediale de arte e novas tecnologias (2011).

Lummo da Espanha foi criado em 2009, o coletivo baseado na cidade de Barcelona é composto pelos artistas Mar Canet, Carles Gutierrez, Jordi Puig e Javier Lloret. O grupo explora, através de experiências interativas e envolventes, o jogo como ferramenta para reivindicar o espaço público como local de convívio e comunicação. Apresentam projetos multidisciplinares construídos pela intersecção de diferentes áreas, tais como arte e tecnologia, arquitetura de mídia, instalações, jogos de computador, etc. Participa ativamente em diversos centros direcionados à produção e investigação da cultura digital, tais como Medialab-Prado em Madrid, Ateleku em Donostia, Hangar em Barcelona e EscuelaLab em Lima.

Além de artista, Mark Essen dos Estados Unidos da América é game designer, e aplica as ideias de cinema de vanguarda aos jogos de vídeo. A maioria de seus jogos recorre a tipos de controles e exige que o jogador seja extremamente preciso. Tornou-se reconhecido internacionalmente em 2007 ao desenvolver a obra de Game Arte "Flyrwrench". Hoje, ele vem sendo apontado como um dos grandes talentos da arte digital contemporânea norte-americana. Atua como professor e na área de pesquisa nos departamentos Game Lab e Design Media da UCLA (University of California, Los Angeles).

Os sentimentos, como elementos psicossociais são outro novo campo de investigação que pretende compreender, modelar e simular o artístico e o sentimento por meio de algoritmos computacionais, como exposto no próximo item.

\section{Conclusão}

A naturalização da tecnologia faz com que ela não seja mais considerada uma extensão do corpo, nem prótese, nem instrumento, mas corpo integrado, pois o cérebro entende como parte do corpo. A produção artística da arte, como gamearte, tanto quanto qualquer outra está inserida no contexto da interação humana com outras atividades. Trabalhos artísticos, mais do que outros, são uma projeção de experiência e de produção de eventos ou artefatos, cujos valores culturais são reconhecidos como artísticos e celebrados como estéticos. As interações com ou- 
tros campos do conhecimento ocorrem frequentemente e mudam há cada época. No entanto, as interações que a arte computacional faz hoje com a tecnociência é sem precedentes, pois a era do processamento da informação global implica redes de conexão e interatividade. Penso que esta experiência trouxe uma descomprometida revolução, com mudança radical na topologia artística e científica como as resultantes da integração do paradigma do processamento da informação e da associação computacional na nossa cultura, como mostrado nas obras de gamearte aqui analisadas.

\section{Referências}

COSTA, Mario. Technologie, production artistique et esthétique de la communication. Art Press, no. 122, 1988.

COSTA, Mario. Le sublime technologique. Collection Un œil, une plume. Lausanne: Iderive, 1994.

DIAS, Flávia. Prorrogada até 14 de abril exibição da mostra Play!Primeira exposição interativa de 'game arte' a céu aberto no Brasil. FIESP. Disponível em:<http:// www.fiesp.com.br/noticias/sesi-sp-abre-mostra-play-diante-de-publico-na-avenida-paulista/. > Acesso em abr. 2013.

MIDIALAB. Sobre o game. Paulista Invaders. Disponível em:<https://paulistainvaders.wordpress.com/>. Acesso em abr. 2013.

PASCULLI, Marisa. Texto release encaminhado para a autora em 2013.

THOMAZ, Andrei. Labirintos Invisíveis. Disponível em:<http://www.andreithomaz. com/arte/labirintos_invisiveis/labirinto2.htm>. Acesso em abr.2013.

WORKS. Grupo Les liens invisibles. Disponível em< http://www.lesliensinvisibles. org/works/. >. Acesso em abr. 2013. 